\title{
A press database on natural risks and its application in the study of floods in Northeastern Spain
}

\author{
M. C. Llasat ${ }^{1}$, M. Llasat-Botija ${ }^{1}$, and L. López ${ }^{2}$ \\ ${ }^{1}$ Department of Astronomy and Meteorology, University of Barcelona, 08028 Barcelona, Spain \\ ${ }^{2}$ Group for Atmospheric Physics, University of León, León, Spain
}

Received: 18 January 2008 - Revised: 3 November 2009 - Accepted: 3 November 2009 - Published: 7 December 2009

\begin{abstract}
The aim of this work is to introduce a systematic press database on natural hazards and climate change in Catalonia (NE of Spain) and to analyze its potential application to social-impact studies. For this reason, a review of the concepts of risk, hazard, vulnerability and social perception is also included. This database has been built for the period 1982-2007 and contains all the news related with those issues published by the oldest still-active newspaper in Catalonia. Some parameters are registered for each article and for each event, including criteria that enable us to determine the importance accorded to it by the newspaper, and a compilation of information about it. This ACCESS data base allows each article to be classified on the basis of the seven defined topics and key words, as well as summary information about the format and structuring of the new itself, the social impact of the event and data about the magnitude or intensity of the event. The coverage given to this type of news has been assessed because of its influence on construction of the social perception of natural risk and climate change, and as a potential source of information about them. The treatment accorded by the press to different risks is also considered. More than 14000 press articles have been classified. Results show that the largest number of news items for the period 1982-2007 relates to forest fires and droughts, followed by floods and heavy rainfalls, although floods are the major risk in the region of study. Two flood events recorded in 2002 have been analyzed in order to show an example of the role of the press information as indicator of risk perception.
\end{abstract}

\section{Introduction}

Following the information provided by the International Strategy for Disaster Reduction (UNISDR, 2009), the top ten natural disasters in the World in 2008 caused 231101 deaths. Most of them were recorded in Asia (98.85\% of total casual-

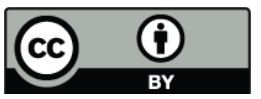

Correspondence to: M. C. Llasat (carmell@am.ub.es) ties in the World), with floods being the most frequent events, although the most catastrophic was Cyclone Nargis that affected Myanmar in May 2008. The same report shows that floods and storms are the main disaster events in the World, followed by earthquakes, extreme temperatures, wildfires, droughts, mass movements and volcanoes. When the period 2000-2007 as a whole is considered the largest percentage of deaths corresponds to Asia (78.69\%), followed by Europe $(15.23 \%)$.

In Europe, floods have been recognized as a major natural risk, in particular after the 1997 Odra flood, the 2001 Vistula flood, and the more destructive 2002 floods on the Elbe, the Danube and their tributaries. A report issued by the European Union in 2003 indicated that the European countries most affected by floods in recent years were France (22\% of damage in Europe) and Italy (17\%). The highest number of casualties due to floods was found in Italy (38\%), followed by Spain $(20 \%)$ and France (17\%). For example, the flood occurring between 8 and 9 September 2002 in the Gard Region (PACA region, France) caused damage amounting to 1.2 billion $€$ and 23 deaths (Legrand et al., 2003). Landslides and rockfalls caused by intense rain are also common in the Mediterranean area, particularly in Italy (Guzzetti et al., 2005), where in 1998 a landslide in Sarno caused 300 deaths.

In the Iberian Peninsula, floods and storms are the main risk, in terms both of economic losses and casualties. Catalonia is one of the areas most widely affected by floods. On 25 September 1962, over 815 people were killed near Barcelona by sudden flash floods produced by an intensely convective event that produced about $250 \mathrm{~mm}$ in just over two hours. At that time the damages were estimated at an amount of 2650 million Ptas. (pesetas), which would correspond to approximately 16 million $€$. Disaster status was declared in Barcelona and national and international aid was received. A total of 217 flood events have been identified in Catalonia for the period 1901-2000 (Barnolas and Llasat, 2007), but their consequences and societal perception has been very different. One of the last catastrophic floods in Catalonia occurred on 10 June 2000, with $215 \mathrm{~mm}$ in three hours. Although the hydrometeorological features and evolution were similar

Published by Copernicus Publications on behalf of the European Geosciences Union. 
to the September 1962 event, economic loss amounted to 65 million $€$ but only three deaths were reported as a direct consequence of the flood, with a further two deaths occurring during the recovery tasks. This event, known as the "Montserrat" event, had a considerable societal impact and has been widely analyzed as an example of Mediterranean flash flooding (Llasat et al., 2003; Mariani et al., 2005; Milelli et al., 2006). Some other flood events have occurred since that episode. Precipitation of over $225 \mathrm{~mm}$ and sea waves of over $8.5 \mathrm{~m}$ were recorded between 16 and 18 October 2003 (Altava-Ortiz et al., 2006). Several rivers overflowed and the sea swell caused severe damage near the coast, but no deaths were reported. In contrast, the flash flood event of 2 August 2005, with $78 \mathrm{~mm}$ in $30 \mathrm{~min}$ (much less precipitation overall) caused one casualty. These differences in the impact of floods are related to the complexity of the factors involved in the risk, such as vulnerability, nature of the hazard, societal perception, the type of the warning system, or aspects of human behavior when people are confronted with danger. The media coverage of these events was different too.

The main aim of this study is to present a systematic natural hazards and climate change press database set up in such a way that for each entry there are over 20 features recorded in relation to the importance accorded it in the newspaper (page number, references to the event on the cover page, inclusion of pictures, etc.). In addition, press data may be contrasted with meteorological data. This database will be very useful in studies on the social perception of risk as represented in press articles. An initial attempt to exemplify the possible applications of this database is the case study included in this paper: the different coverage given by the press to two different flood events in Catalonia - the floods on 8-10 October 2002 and the floods on 9-12 April of the same year. In order to have a better discussion the paper starts with the presentation of an overview about risk and social perception.

\section{Risk and societal perception: an overview}

\subsection{Risk}

Following the UNISDR (United Nations, International Strategy for Disaster Reduction) terminology (2009) the term "risk" refers to the "combination of the probability of an event and its negative consequences". The UNISDR itself notes that "risk" has two distinctive connotations: the popular one that emphasizes the concept of chance or possibility, and the technical one in which the emphasis is usually placed on the consequences, in terms of "potential losses" for some particular cause, place and period. Besides this, the concept of natural risk' varies depending on the disciplines (Cardona, 2004; Slovic and Weber, 2002), especially between the physical and the social sciences. Today we find many different definitions for this concept or for the various components of the concept.
In this paper "risk" will be defined as the potential loss to the exposed subject or system, resulting from the convolution (a mathematical concept that refers to concomitance and mutual conditioning) of hazard and vulnerability.

\subsection{Hazard}

The term "hazard" refers to a dangerous phenomenon, substance, human activity or condition that may cause loss of life, injury or other health impacts, property damage, loss of livelihoods and services, social and economic disruption, or environmental damage (UNISDR, 2009). It involves considering the frequency and the intensity of the threatening event (Lastoria et al., 2006) and can be expressed in mathematical form as the probability of occurrence of an event of a certain intensity in a specific site over a specific time of exposure (Cardona, 2004).

\subsection{Vulnerability}

Many of the current approaches to the study of natural risks are considered to be ineffective because they are based exclusively on hazard and not on the conditions that favor the occurrence of the phenomenon, that is, the other risk element: vulnerability. The term "vulnerability" considers "the characteristics and circumstances of a community, system or asset that make it susceptible to the damaging effects of a hazard" (UNISDR, 2009). In other words, vulnerability represents the physical, economic, political or social susceptibility or predisposition of a community to damage if a destabilizing phenomenon of natural or anthropogenic origin was to occur (Cardona, 2004). Lastoria et al. (2006) argue that "vulnerability" represents the attitude of an entity towards being damaged or destroyed. Some authors broaden this definition and indicate that vulnerability refers to the lack of capacity to protect oneself and to survive a catastrophe. Moreover, "vulnerability has also been defined as person or group characteristics that influence their capacity to anticipate, deal with, resist, and recuperate from impact of a natural hazard" (Blaikie et al., 1994).

It is crucial to note that vulnerability is socially constructed and is the result of economic, social and political processes (Cardona, 2004). Social vulnerability is not a predefined condition, but rather gradually built up by accumulation and relatively stable in time. In contrast, Tingsanchali and Karim (2005) suggest that the vulnerability factor is proportional to population density, and some authors even link vulnerability with poverty. This is not a straightforward relationship, however. Vulnerability has to be modeled taking into account social factors, such as the strength of family links and the collective economy, the existence of basic social facilities, the presence of ethnic and political discrimination, the existence of educational opportunities, and other factors (Cardona, 1993, 1996). A number of studies have demonstrated that within a particular society, there are groups that 
are more vulnerable than others when faced with natural hazards, such as the handicapped, the poor, ethnic minorities and women.

When considering physical vulnerability, the exposure of different types of people and buildings as well as indirect damages must be taken into account (Messner and Meyer, 2006). When considering floods, the urbanization of the floodplains of many rivers has resulted in a significant increase in physical vulnerability over the past few years. Vulnerability to flooding of small ground-level family houses is quite different from vulnerability in 10 or more apartment houses, where only the ground floor is flooded. These factors had lately gained more importance.

\subsection{Risk perception}

People do not necessarily share the same perceptions of the significance and underlying causes of different risks. In this sense, Burton et al. (1978) argues that natural phenomena are "neutral" and that the location of people, their actions and perceptions, is what identifies natural phenomena as resources or as dangers. Thus, the individual and the social perception are essential in defining the term "risk". For example, snow is a natural resource when it falls on ski slopes, but it becomes a risk for those driving to the winter resorts if it also falls on the roads. It may be claimed, then, that the concept of "natural risk" is relative, acquiring full meaning only in relation to a number of socio-cultural and psychological considerations. (García Codrón and Silió Cervera, 2000; Slovic and Weber, 2002). Whyte (1986) distinguish three groups of factors influencing amplification of the perceived risk: personal characteristics, situational factors (media attention and others) and risk characteristics.

From the 1980s, a large number of studies have focused on the fact that the perception of risks is built socially (Beck, 1992; Hoffman and Oliver-Smith, 2002; Peretti-Watel, 2001; Plapp, 2001). Several authors claim that the social perception of risks and the levels of acceptance of these risks are constructed collectively, in much the same way as language or aesthetic judgments (Douglas and Wildavsky, 1983). As a consequence, this perception will depend on the dominant patterns and beliefs in a particular society, i.e., on its culture. This explains why tolerance thresholds with respect to certain risks vary so much from one society to another. On the other hand, risks that are constructed socially are experienced differently by different individuals or groups of individuals within one particular society, thereby leading to multiple individual perceptions of one and the same event (Hoffman and Oliver-Smith, 2002).

Consequently the risk perception can be studied following different approaches. Weber (2001) and Slovic and Weber (2002) propose three approaches: the axiomatic measurement paradigm, the socio-cultural paradigm, and the psychometric paradigm. The first focuses on the way in which people subjectively transform risk information; the second analyzes the effect of group-and culture-level variables on risk perception. Finally, the third approach identifies people's emotional reactions to risk situations. Following Plapp (2001), the aim of this last approach is to unveil the cognitive structure of risk; in contrast, the socio-cultural approach posits affiliations with social ways of living and corresponding worldviews that tend to determine the selection of those risks as the most harmful ones on the basis of their value orientations.

When public perception and its evolution are analyzed it is necessary to distinguish between the different factors that could be involved in it (Brilly and Polic, 2005). A factor analysis allows a distinction to be drawn between two main factors: those related to the perception as such (Slovic, 1992, 1997, 2000; Slovic and Weber, 2002), and those related to the natural risk occurrence. In its turn, the social perception analysis depends on the dominant approach.

\subsection{Risk analysis through the media}

Press information can be analyzed from the three previous paradigms: the news item itself reflects the transformation of objective data into a subjective message (i.e. the headlines); the socio-cultural values gives a lower or higher profile to a hazard (i.e. the importance of the ecological impact); and, finally, mass-media have a strong impact on the ordering of perceiving risks and associated emotions to a specific disaster (i.e. some pictures or descriptions). There have been some previous studies that argue the case for use of the press to estimate the social perception of natural risks or climate change (Allan et al., 2000; Delitala, 2005; Lacey and Longman, 1997; Fischer, 1998; Llasat-Botija et al., 2007). The majority approach the use of the press like a proxy-data source to obtain indirect information about frequency and risk magnitude, or a socio-cultural approach.

The media are among the most important sources of disaster information and they significantly influence or shape how the population and the government view, perceive, and respond to hazards and disasters. Fischer (1998) points out that "if most Americans rely on the various forms of mass media to obtain their information about what occurs before, during and after a disaster, then it stands to reason that the accuracy of their perception is dependent upon the media". All the studies suggest that the power of the mass media in the perception of a natural disaster, for example floods, is considerable. Besides this, the recent increase in the number of extreme weather events is often associated with global climate change. Indeed, the number of references to climate change in the press has soared in the past few years (Llasat and Llasat-Botija, 2008; Serra et al., 2008). The fear of risks that have always been there may be eclipsed by the fear caused by an increase in the number of other human-induced natural hazards, even if they are less intense phenomena usually related to climate change. "It seems that the fear of local risks acquires greater legitimacy when these risks are linked 
Table 1. Topic classification used in the database.

\begin{tabular}{llc}
\hline Topic & Description & Code \\
\hline Floods & Floods, landslides caused by rain. & 1 \\
Storms & Sea storm, wind storm, tornado, hurricane, waves, sand storm. & 2 \\
Snow and cold waves & Snowfalls, cold wave, snow slide. & 3 \\
Agro-meteorological risks & Frost, hail, (lightning), drought, heat wave, forest fires. & 4 \\
Sustainable development & Climate change, Pollution, bioclimatology, ozone layer, & \\
& historical series, statistics, energy, environment & 5 \\
Alert chain and prevention & Training, forecasts, warnings, mass-media, public works & 6 \\
Others & Earthquakes, volcanoes, etc. & 7 \\
\hline
\end{tabular}

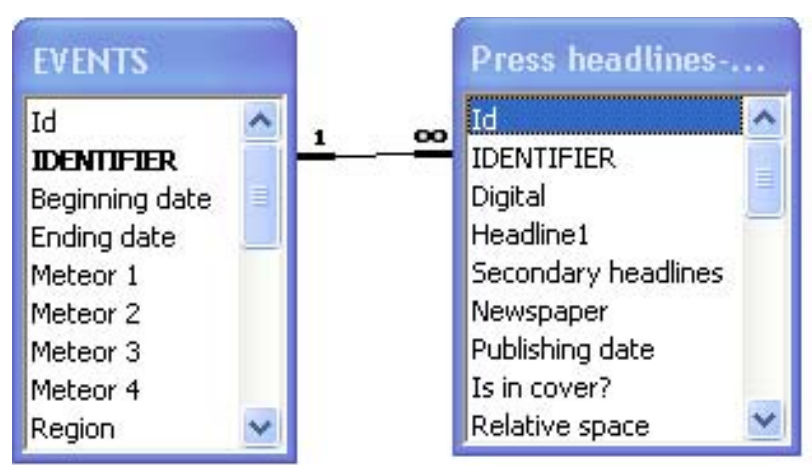

Fig. 1. Structure of the ACCESS database.

to global problems that attract greater scientific and media interest" (García Codrón and Silió Cervera, 2000).

Finally, a recent analysis of droughts and flood coverage by the press in Catalonia has revealed relatively good accuracy in the relationship between the number of flood events and droughts identified by the press and the flood events and drought periods recorded, pointing to the use of the press as an indirect indicator of risk evolution (Llasat et al., 2009).

\section{Database}

The Natural Hazards Analysis Team (GAMA in its Spanish acronym, "Grupo de Análisis de Situaciones Meteorológicas Adversas") of the University of Barcelona began the compilation of press articles related to natural risks in 1982. Although for some events such as the two included in this paper, different newspapers were considered, this study focuses on the systematic analysis of the newspaper La Vanguardia. It has been chosen because of it is one of the most important newspapers in Catalonia and the fourth most important in Spain (on average, over 200000 copies are sold daily). All daily news items from 1982 until 2007 were consulted in its archives as well as in its more recent digital library (http://www.lavanguardia.es/hemeroteca). The PRESS-GAMA database currently contains more than
14200 news items on natural hazards, climatic change and sustainable development, 12584 of which are from La Vanguardia.

The selected articles have been classified into seven groups or topics as shown in Table 1. An identification code is assigned to each article, enabling us to relate them to the topic and event they refer to. The information is stored in a Relational Database created in Access. This database consists of four tables (Fig. 1): two primary tables entitled "Events", that include topics 1, 2, 3, 4, and 7, and "Themes" (topics 5 and 6) that contain, respectively, summary information about each event (i.e., the flood recorded on 10 June 2000) and news items related with risk assessment, risk management, sustainable development and climate change (i.e., the new Directive on Civil Protection or the presentation of the IPCC). For each Event, information about the date on which it occurred, the publication date, the kind of risk and key words, as well as data about the magnitude or intensity of the event as published in the newspaper (i.e. total rainfall amount) is entered. This last information can be checked and completed with hydrological and meteorological information provided by other databases of the GAMA group (i.e. INUNGAMA, see Barnolas and Llasat, 2007) or from data of meteorological and hydrological services. 
Table 2. Statistical data corresponding to the annual number of headlines for each Topic, for the period 1982-2007.

\begin{tabular}{llccccccc}
\hline N Topic & & 1 & 2 & 3 & 4 & 5 & 6 & 7 \\
\hline Total & Number news & 2685 & 836 & 1593 & 3163 & 1506 & 1404 & 1370 \\
& Annual average & 103 & 32 & 61 & 122 & 58 & 54 & 53 \\
& Standard deviation & 71.8 & 26.1 & 38.1 & 83.4 & 62.7 & 40 & 34.7 \\
Catalonia & Number news & 1501 & 237 & 1242 & 2323 & 1153 & 1199 & 221 \\
& Annual average & 58 & 9 & 48 & 89 & 44 & 46 & 9 \\
& Standard deviation & 46.1 & 9.7 & 37.6 & 69.2 & 53.4 & 28.2 & 21.2 \\
\hline
\end{tabular}

In second place are two related tables: "Press headlinesEvents" and "Press headlines-Themes", linked with "Events" and "Themes" tables respectively. It is important to emphasize that a single event, for example a flash flood, can consist of more than one headline, i.e. more than one article. These tables contain all the information about the news items in relation to form and content: name of newspaper, headline and subtitle(s), date of publication, page number or whether or not the article appears on the cover, space occupied by the article with respect to the rest of the page, location of the article on the page, number of columns, number of pictures and/or diagrams, date of beginning of the event, whether or not it affected Catalonia, meteors or other important topics in the article, towns affected, region, economic losses, casualties. Other fields allow for the inclusion of a short description of the article or comments such as the type of article (editorial, opinion, news, etc.). These parameters are useful if we intend to analyze the importance accorded by the written press to this type of news, which is also related to the general line followed by the newspaper (Duce Díaz, 2002). For example, an article on floods on the cover page, with references on the odd-numbered pages (the ones that are read first), in several columns, with pictures and diagrams, indicates a strong impact or coverage in the press. And this is related to the way in which the population perceives the importance of the event.

This ACCESS relational database makes it easy to carry out specific searches by date, type of phenomenon, place, etc. This database provides data for different analyses, such as the quantitative evaluation of the impact of each risk, or the progress of the press coverage of each risk type over the study period.

\section{Preliminary applications of the PRESS-GAMA database}

\subsection{Analysis of the period 1982-2007}

Figure 2 shows the distribution of the number of articles or headlines by topics and Table 2 shows the statistics. Related with natural phenomena, in first place of importance,

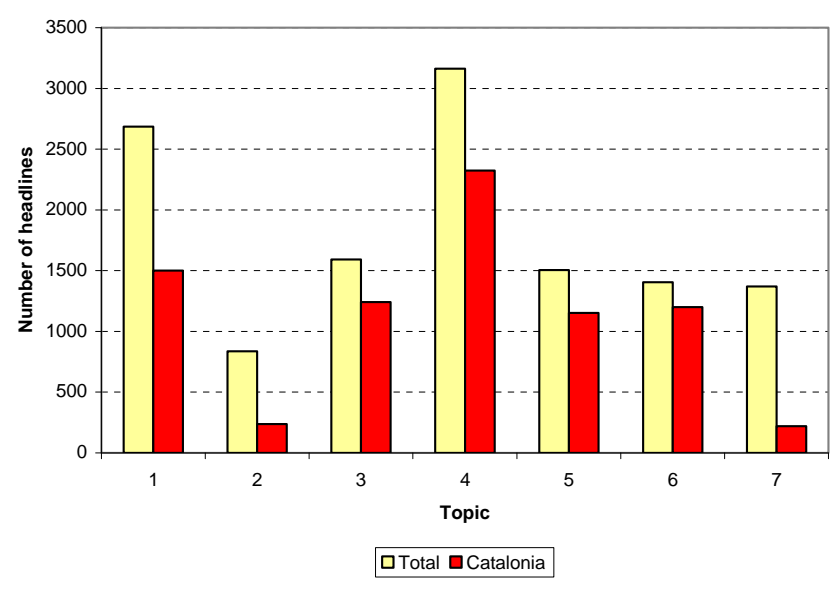

Fig. 2. Number of headlines classified by topic in Catalonia and in all regions from 1982 to 2007 ( 1 = floods, $2=$ wind storms, $3=$ snow and cold waves, $4=$ agro-meteorological risks, $5=$ climate change, $6=$ alert chain and prevention, and $7=$ others).

are agrometeorological risks (forest fires and droughts, basically) that account for 3163 articles, 2323 of which refer to episodes arising in Catalonia. In second place, floods and significant rain events account for a further 2685 articles, 1501 of which refer to episodes in Catalonia. This means that even though the most important natural risks in Catalonia are associated with heavy rainfall events and floods, the social perception of flood risk measured indirectly by the number of headlines in the press, is not proportionally as high as expected. Next come snow and cold spells, and finally wind storms. Other risks like volcanoes or earthquakes have a minor number of news items, due to their low frequency in Catalonia.

As far as differences between floods occurring in Catalonia and elsewhere are concerned, it may be noted that articles dealing with local floods and heavy rains amount to $56 \%$ of the total number of articles about floods. In the case of forest fires and droughts (agrometeorological risks) and snowfalls (snow- and cold-related risks), the percentages of headlines relating to local events soar to $73 \%$ and $78 \%$, respectively. 


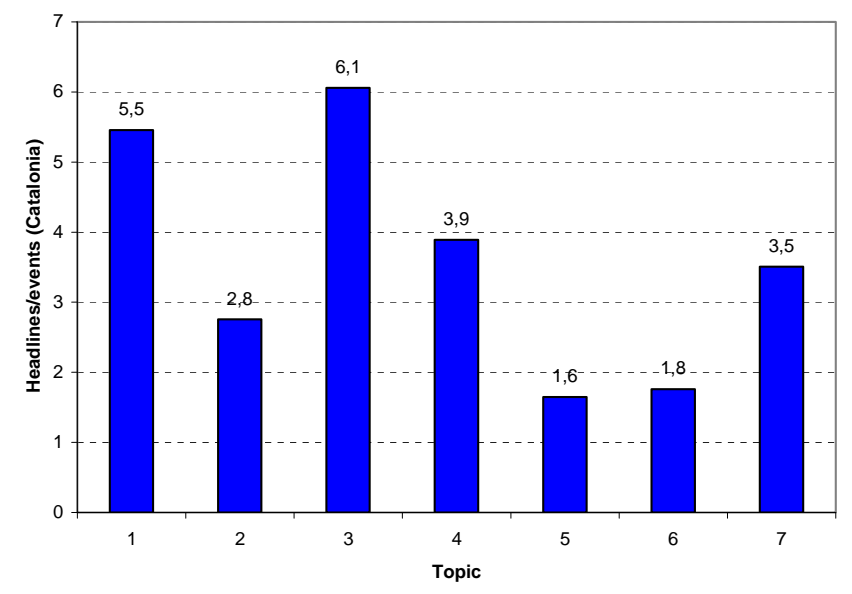

Fig. 3. Relationship between the number of headlines published and the number of events to which they refer in Catalonia between 1982 and 2007.

These data confirm what might have been predicted: the social perception assessed using newspaper articles accords greater importance to events occurring locally than to events elsewhere, where the consequences do not affect that particular population directly. This interest is especially noticeable in the case of forest fires, since the loss of a natural resource for economic uses or simply for leisure activities has an important local impact that is increased when residential zones are affected by forest fires. Another important factor to be considered is the season of the year: minor forest fires have a strong impact in the press in summer, when government is in holiday and there is a scarcity of news. On the other hand, the higher frequency of disasters in the world related with floods is reflected in this $44 \%$ of news items relating to floods recorded abroad.

In order to analyze in detail the importance of the various topics in the local press, the ratio of the number of headlines versus the number of events was calculated for the events recorded in Catalonia. This enables us to assess the importance accorded by the press better than by using only the number of events or the number of headlines. Figure 3 reveals that this ratio is 5.5 for topic 1 ; that is, for each event there is an average of 5.5 articles in the press. In the case of topics 4 and 3, the impact indices are 3.9 and 6.1, respectively. The snow risk in Catalonia is low (regular snow events in the mountains are not considered as a risk), and when an event such as the one in December 2001 that affected the central and coastal regions occurs, there is a considerable massmedia coverage. On the other hand, the high number of small forest fires with low impact is reflected in this lower ratio.

Since 1982, four major catastrophic forest fires have occurred (1986, 1994, 1998, and 2003) compared with eleven catastrophic flood events (1982, 1983, 1987, 1988, 1989, 1994, 1995, 1996, 2000, 2005, and 2006), and every year

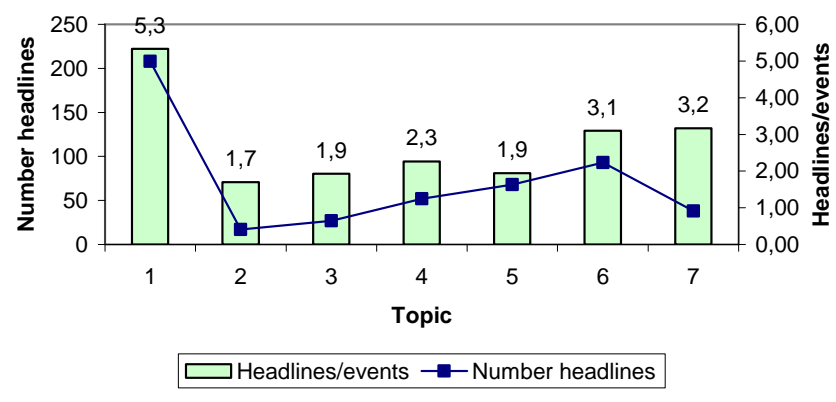

Fig. 4. Number of headlines and relationship between the number of headlines published and the number of events to which they refer for the year 2002 .

there are some casualties due to floods. This means that floods are the leading natural hazard in Catalonia (Llasat, 2009), although the number of headlines does not reveal this fact. This result coincides with those of other studies (Cutter, 1993; Enander, 2005; Skiple Ibreek et al., 2005) which point to floods as a hazard that tends to be viewed as natural and familiar, a factor that may reduce the perceived seriousness of the hazard itself. People tend to underestimate the frequency of common events that are fairly likely, but are perceived to have less serious consequences.

These ratios are an average for the entire period 19822007 and can vary greatly year by year. Figure 4 shows the number of headlines for the year 2002 as well as the ratio between headlines/events. In that year, the highest number of news items on natural risks was related with floods: 208 news items, of which 128 related to floods recorded in Catalonia. The highest ratio of headlines per event was also for topic 1: 5.3 news items/event, value that increases to 8.0 news items/event when related only to Catalonia. The following section analyzes the two main flood events that gave rise to this broad press coverage. Figure 5 shows the monthly distribution of news for that year. The seasonality of the events is clearly reflected in the press, although the effect of some minor risks is overestimated by the press. August recorded the major number of headlines about the topics analyzed in this paper. August is a month usually characterised by flash-flood events and forest fires, but it also coincides with the holidays of the Spanish Parliament and Catalan Parliament, so that the number of news items related with political issues is less than for the other months. The analysis of news items related with topic one points to this probable summer overestimation: the most important flood events in Catalonia, in year 2002, occurred in April and October. Most of the news items about floods in August 2002 were about the floods that affected Central Europe, as well as one flash flood event recorded on 31 July.

Furthermore, the inter-annual distribution of news can change from one year to another. Figure 6a shows a clear positive trend in the annual number of headlines for 
the period 1982-2007. Figure 6b shows the same analysis when topics 1-4 are separated from the themes related with sustainable development, climate change and prevention measures (topics 5 and 6). Topic 7 has a lower contribution, with the exception of the year 2006 when subsidence occurred in the city of Barcelona as a consequence of some public works. The importance achieved by climate change in recent years is evident, and may contribute to this positive trend. Besides, this increase can be related with changes in the frequency of the phenomena, vulnerability and the press treatment. The following section outlines an example concerning this last issue.

\subsection{Case studies: two episodes of extraordinary floods in 2002 with different social impact}

Following the classification proposed by Llasat et al. (2003), two extraordinary flood events affected Catalonia in April 2002 and October 2002, respectively. The first affected the northern part of Catalonia and caused some little rivers to burst their banks; the second recorded less precipitation and lower rainfall rates, but affected a densely populated area. Figure 7 shows the flood risk map developed by the Government of Catalonia within the framework of the INUNCAT Plan (DGPC, 2006). The April event affected a region with low flood risk, while the October event affected another region with high flood risk. This part compares the different press coverage accorded to the two events.

\subsubsection{Episode 9-12 April 2002}

Between 9 and 12 April the accumulated precipitation registered at some weather stations in the region known as the Alt Empordà (northern part of Catalonia) was over $240 \mathrm{~mm}$, with a maximum of $345.7 \mathrm{~mm}$ in Boadella, 321.7 of which was recorded in $24 \mathrm{~h}$. Figure 8 shows the rain distribution and the $\beta$ field (percentage of convective precipitation versus total precipitation, see Llasat, 2001) for the entire time span. The latter reaches values of only $53 \%$, but the figure soars to nearly $60 \%$ in $24 \mathrm{~h}$ at the Boadella weather station. The distribution of accumulated precipitation at this station was $275.1 \mathrm{~mm} / 12 \mathrm{~h}, 237.5 \mathrm{~mm} / 6 \mathrm{~h}$ and $66.2 \mathrm{~mm} / 1 \mathrm{~h}$. The heavy rain was accompanied by a strong wind storm affecting the whole of Catalonia with gusts of more than $128 \mathrm{~km} / \mathrm{h}$ and waves more than $5 \mathrm{~m}$ high. Snow was registered in some mountainous areas.

The rivers Llobregat de l'Empordà and Manol overflowed their banks; there were power cuts (over 5000 people were affected), communication networks were cut too, and some small towns were literally divided into two by the sudden flood. Firemen attended 150 incidents and many basements and parking lots were flooded. Damages to crops was also recorded. However, fewer headlines were devoted to this event (13 in La Vanguardia) and only a few minutes in the TV news.

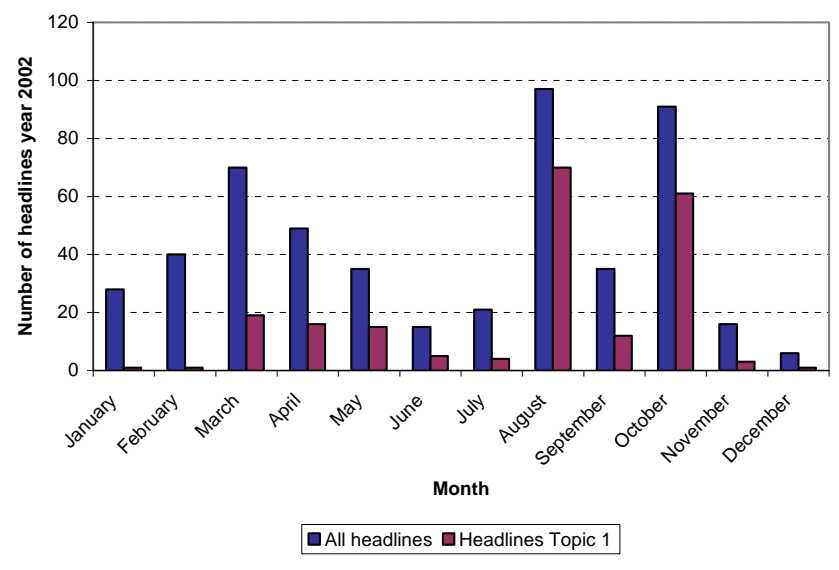

Fig. 5. Monthly distribution of the total number of news items for year 2002. The same for topic 1 .

\subsubsection{Episode 8-10 October 2002}

Heavy rain fell along the central coast of Catalonia during this event. The rainfall began in Tarragona and swept the whole of Catalonia, with the most intense precipitation along the coast. The maximum of $196.5 \mathrm{~mm}$ was registered in the basins of Baix Llobregat and Garraf counties, $174.1 \mathrm{~mm}$ of which were registered in $24 \mathrm{~h}$ (Fig. 9). The maximum values for time intervals shorter than $24 \mathrm{~h}$ were $162.4 \mathrm{~mm} / 12 \mathrm{~h}$, $127.7 \mathrm{~mm} / 6 \mathrm{~h}$, and $50.2 \mathrm{~mm} / 1 \mathrm{~h}$. Figure $9 \mathrm{~b}$ shows the $\beta$ field: maximum levels of over $40 \%$ were registered in the Baix Llobregat and Garraf basins.

Firemen attended 370 incidents and there were major power cuts with over 30000 people affected. About 1000 cars were trapped in an enormous traffic jam that lasted for $6 \mathrm{~h}$ when the highway between Castelldefels and Barcelona was cut. The subway and trains were also affected. The control center at the airport was flooded and more than 200 flights had to be canceled. Many buildings suffered damage on their ground floors and in basements. One building and part of another were swept away by the flood, neither of them inhabited. There were also significant losses in agriculture.

All in all, including short pieces and articles on the cover page, there were 60 articles in the La Vanguardia daily newspaper, including the main article (Fig. 10). The local television channel devoted most of the daily news program to the event, as well as an additional special program. Some headlines did not refer directly to the flood, but to the inauguration of the new flooded terminal and to tension between members of different political parties.

\subsubsection{Comparison between the two events}

The difference in the perception of the two events based exclusively on newspaper articles suggests that the second event was considered to be the one with the higher risk of the two. Although accumulated precipitation and intensity were 


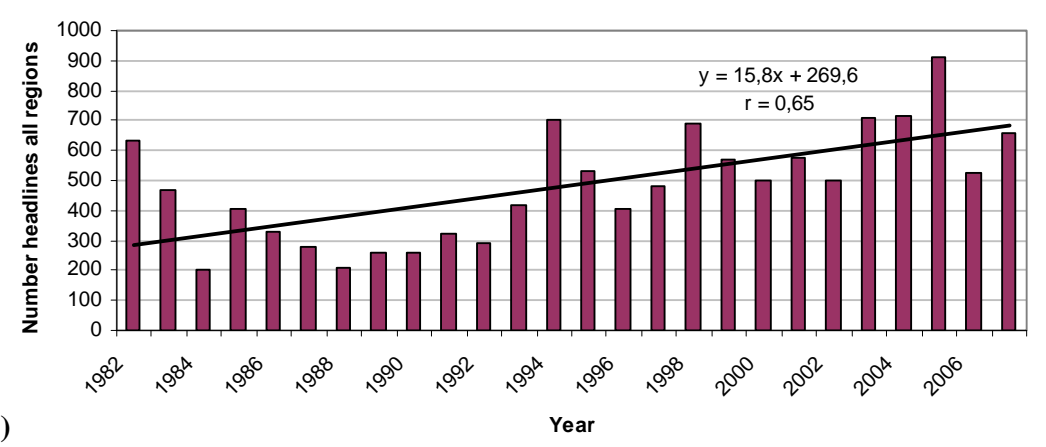

(a)

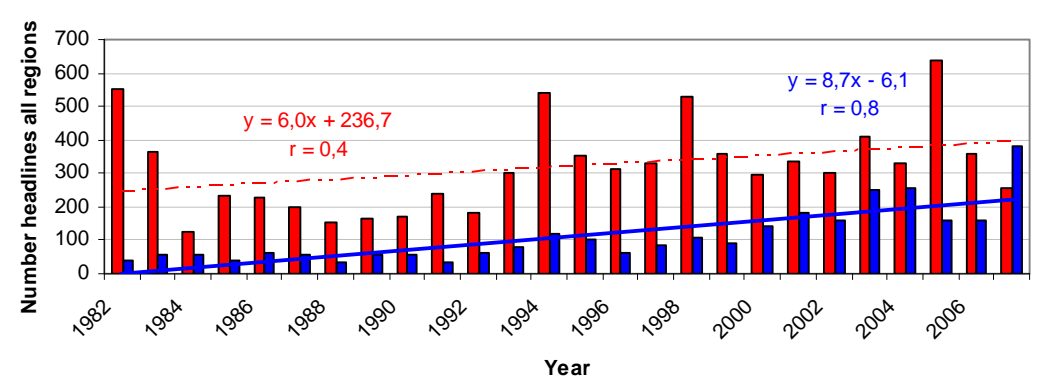

(b)

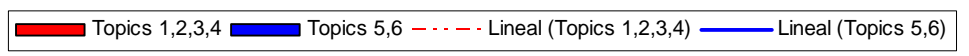

Fig. 6. Evolution of the total number of news items (a) and news items separated into two topic groups (1-4 and 5-6) for the period 1982-2007 (b).

Table 3. Variables extracted from the press database for the events on 8-10 October 2002 and 9-12 April 2002.

\begin{tabular}{lll}
\hline & $\begin{array}{l}\text { October } \\
2002\end{array}$ & $\begin{array}{l}\text { April } \\
2002\end{array}$ \\
\hline Number of headlines & $58+2$ covers & $11+2$ cover pages \\
Space occupied (\%) & 16.11 & 5.05 \\
Pictures & 34 & 12 \\
Graph & 11 & 0 \\
Columns & 128 & 30 \\
Upper part of the page & $31(53 \%)$ & $5(45 \%)$ \\
Lower part of the page & 7 & 3 \\
Middle of the page & 17 & 1 \\
Whole page & 3 & 2 \\
Left side of the page & 13 & 1 \\
Right side of the page & $16(27 \%)$ & $4(36 \%)$ \\
Middle of the page & 11 & 0 \\
Articles on even pages & $22 / 58(38 \%)$ & $5 / 11(45 \%)$ \\
Articles on odd pages & 36 & 6 \\
\hline
\end{tabular}

greater in the April event, the flood risk seems more acute in the event in October. This fact may be attributed to the different vulnerability of the two areas.

Table 3 shows that the October event filled 128 columns in the newspaper, including all 58 articles in inside pages. In addition, 34 pictures and 11 graphs explaining the damages and the event evolution were published in relation to this event. The April event filled 30 columns, and 12 pictures were published. Besides this, in the case of the latter event most articles were published on even-numbered pages and on the upper parts of the page, i.e., the ones that have a lower visual impact on the reader. Finally, the news items about the April case were concentrated between 11 and 15 April (3 days after the flood event), while for the October case, although the maximum number was concentrated on 10 and 11 October (46 news items), some news coverage continued up to one month after the event.

The vulnerability was much higher in the second case. For example, the town of Castelldefels has nearly doubled its population in the past 20 years, rising from 24000 inhabitants to 46000 . In this town, the CCS ("Consorcio de Compensación de Seguros", a public insurance company) payed out $1858000 €$ in compensation for damage to infrastructures and urban furniture. However, the CCS paid more than $12000000 €$ for damages caused in the region between 8 and 10 October. The insurance companies paid out $28885200 €$ in 2002 in compensation for damages caused by floods, of which $24714080 €$ corresponded to the province of Barcelona. The growth of towns close to river beds and in areas that are potentially floodable has greatly increased physical vulnerability in the past 20 years. This phenomenon is not new. Skiple Ibreek et al. (2005) carried out a study on the social perception of floods, and the people surveyed attributed the higher flood hazard to increasing and poorly controlled new developments in flood-prone areas. 


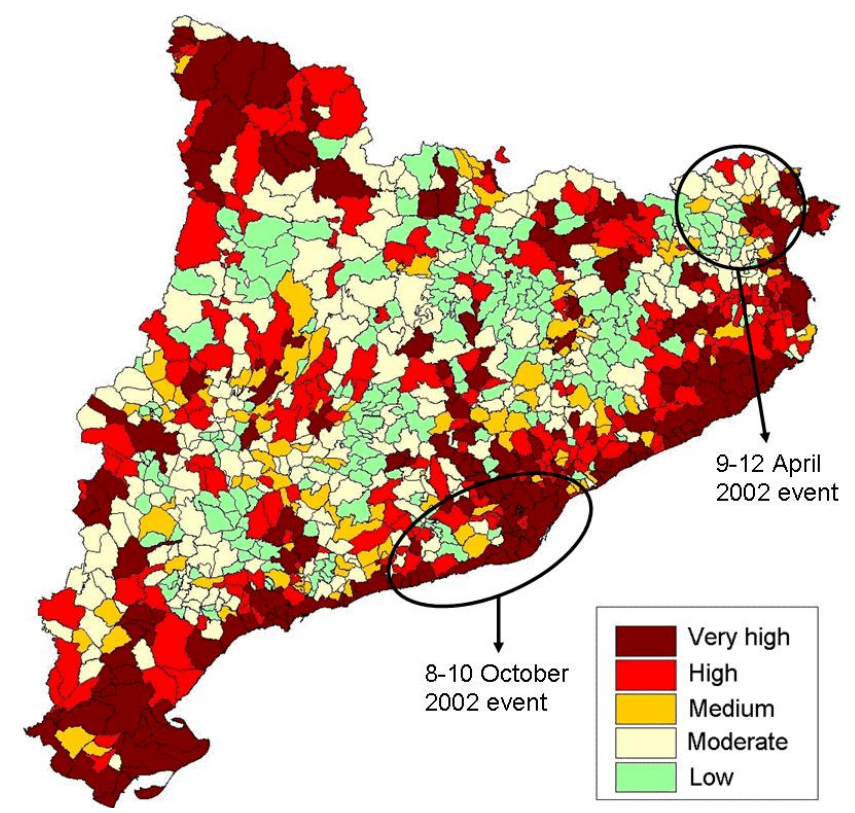

Fig. 7. Map of Catalonia showing the flood risk level for each municipality (extracted from INUNCAT).

Flood risk may have increased owing to a number of changes in land use which induce changes in the hydrological systems. Deforestation, urbanization, and reduction of wetlands decrease the water storage capacity in the catchment areas and increase the runoff coefficient. Urbanization has influenced flood hazard adversely in many watersheds by increasing the impervious area (roofs, roads, pavements, parking lots, etc.) (Kundzewicz and Mendel, 2003).

In addition, the impact of urbanization on flood risk depends on the type of flood-inducing precipitation - land-use changes may play a more prominent role for convective precipitation than for advective precipitation (Kundzewicz and Mendel, 2003). This result is particularly relevant in the case of Catalonia, since the $\beta$ distribution field (Llasat, 2001) measuring the percentage of convective precipitation when compared with the total accumulated precipitation is very high, and flash floods are frequent.

Communication networks are especially important today in Catalonia, since they link Barcelona with smaller suburban commuter towns. Changes in these networks will always have a high impact in the media. García Codrón and Silió Cervera (2000) claim that our dependence on communication networks is growing. Road cuts block transport, isolate towns and villages, attract the attention of the media and become the main topic of conversation. Until a few decades ago these factors did not receive much attention. The consequences of a particular phenomenon change over time, as does their perception, even though the phenomenon itself remains unchanged. (a)

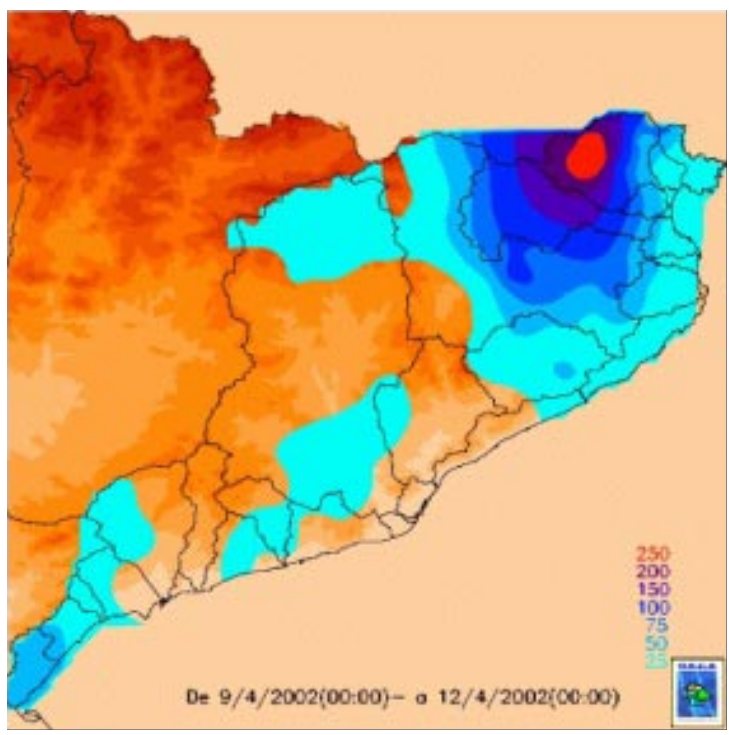

(b)

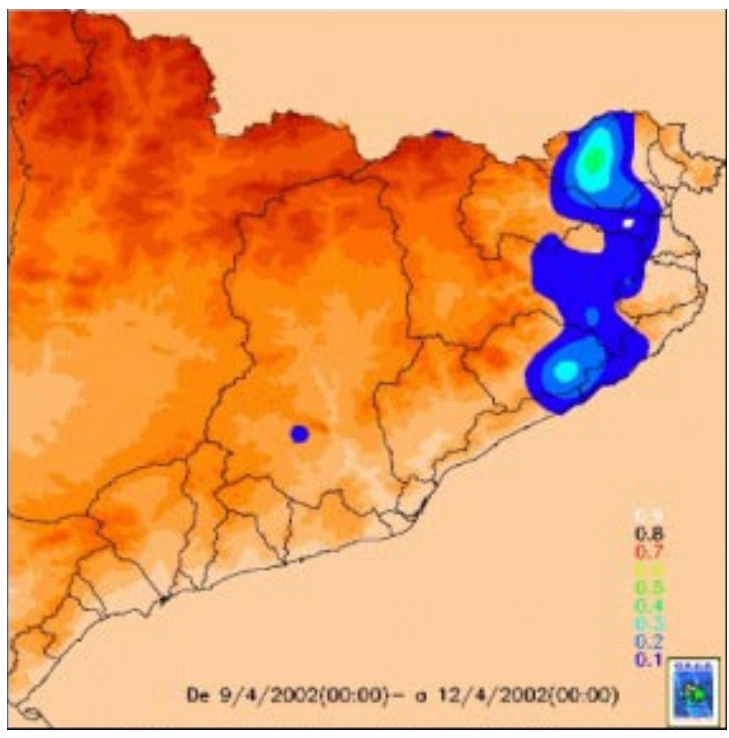

Fig. 8. Episode 9-12 April 2002. (a) Distribution of accumulated rain in the internal basins of Catalonia between 9 April 2002 at 00:00 UTC and 12 April at the same time; (b) $\beta$ field distribution for the same time span.

On the other hand, the political tension generated by the episode on 8-10 October meant that it appeared in the press for several days. Platt (1999) referred to information on what the National Academy of Public Administration has called the "CNN Syndrome" when he stated: "Few emergencies and disasters will remain local - most will now be "nationalized" and politicized as a result of media coverage". Other authors argue that local politicians try to boost disasters to achieve national relevance and so obtain state funds in compensation. In the first case study (8-10 October 2002) the mayor of Castelldefels wanted the area to be declared a disaster zone, even though there had already been floods in the area on 12 September 2002. 
(a)

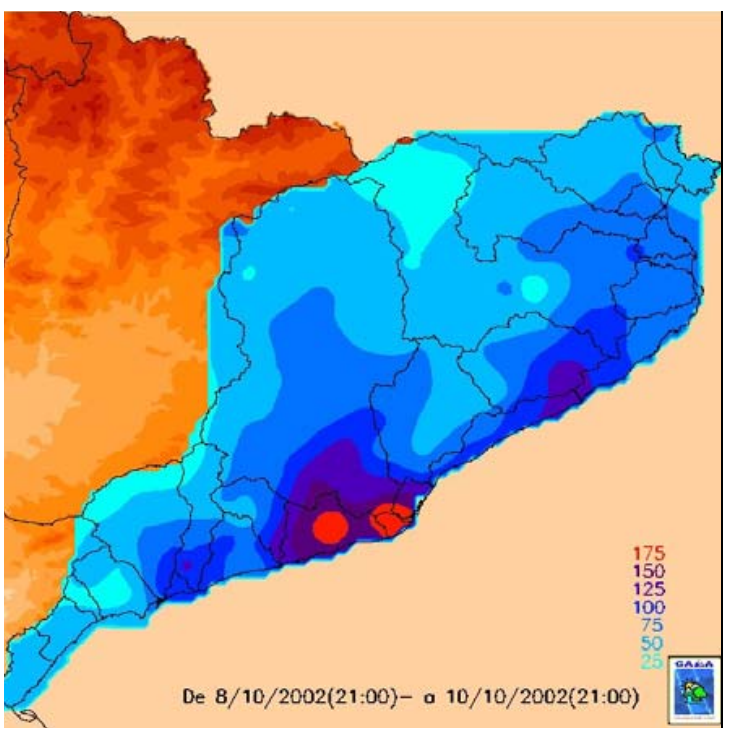

(b)

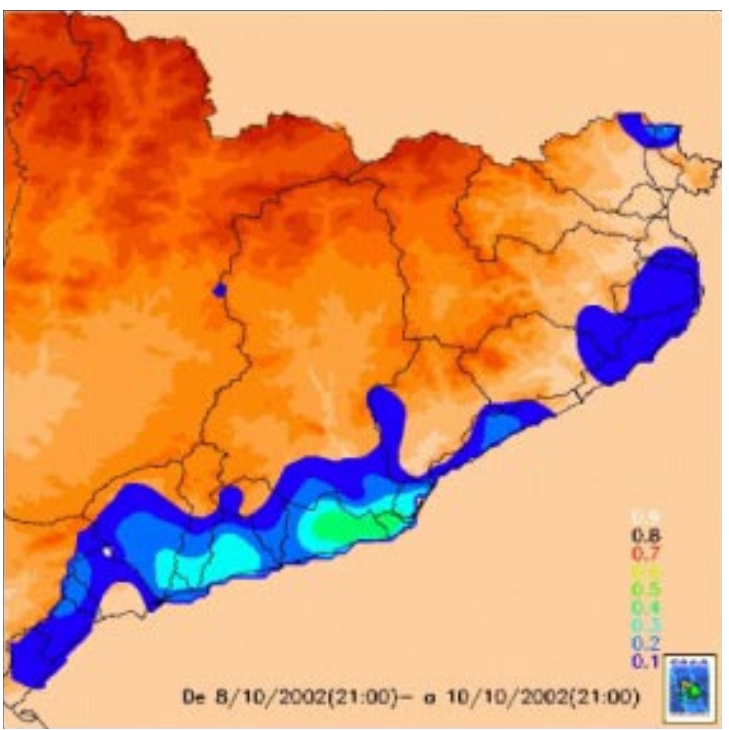

Fig. 9. Episode 8-10 October 2002. (a) Distribution of rain in the internal basins of Catalonia between 8 October 2002 at 21:00 UTC, and 10 October 2002 at the same time; (b) $\beta$ field distribution for the same time span.

In the first case study, the population exposed was smaller and the damage caused seemed less important. No significant political disputes arose and the media coverage was much less extensive. This case clearly exemplifies that it is wrong to consider hazard maps as equivalent to flood risk maps, since vulnerability plays a key role here. For a more comprehensive comparison, it is necessary to compare damages and casualties caused by events of similar intensity hitting the same areas (Lastoria et al., 2006).

\section{LAVANGUARDIA} Caos tras la lluvia

Graves imundaciones y Atascos kilométricos zonas incomunicadas en el y conductores atrapados Baix Llobregat y el Garraf en los accesos a Barcelona intensificarse el dia de hoy

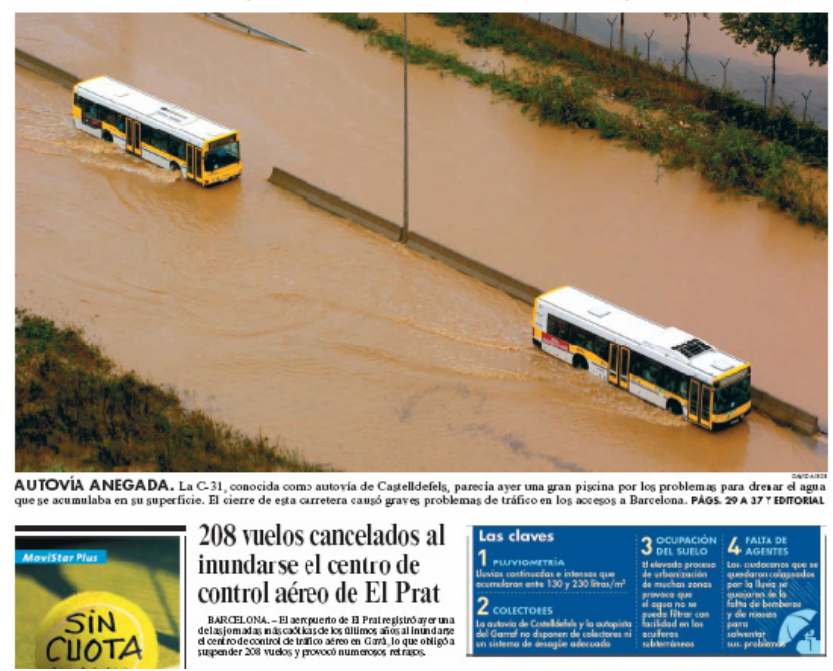

Fig. 10. Frontpage of La Vanguardia corresponding to the October 2002 floods in Catalonia.

A last comment should be made. Most of the people living in floodplains affected by the April event had an old "floodculture", and consequently, pre-event adaptations and adequate in-event responses minimized tangible and intangible damages (Nunes Correia et al., 1998). On the other hand, many inhabitants of floodplains near Barcelona (as was the case of the second event) do not know that they live in floodplains, ignore that fact or have a false perception of security, and, consequently, often take decisions in relative ignorance of the real conditions.

\section{Conclusions}

Press articles can be used to obtain an indirect estimation of the risk, where the term "risk" refers to the combination of the probability of an event (hazard) and its potential negative consequences (vulnerability). The media, and particularly the press, can also be used to estimate the social perception of natural risks and climate change: usually the press reflects the dominant patterns and beliefs in a particular society, and, in its turn, has a strong influence on the collective construction of the risk perception, independently 
of the multiple individual perceptions and experiences of the same event or risk. Risk perception can be studied following three different approaches: the axiomatic measurement paradigm, the socio-cultural paradigm, and the psychometric paradigm. When public perception and its evolution are analyzed through the press information, it is necessary to distinguish between the different factors that could be involved in it: those related to the natural risk occurrence, including hazard and vulnerability, and those related to the perception as such, basically analyzed from the socio-cultural paradigm approach.

Coming from these hypotheses, a systematic compilation of newspaper articles on natural hazards and climate change published between 1982 and 2007 by the Spanish journal $L a$ Vanguardia, has been made. The database is formed by several interrelated tables that will enable us to carry out studies on the media coverage of certain events or topics, the evolution of the number of articles on a particular topic, the comparison of the data published in the press with data from meteorological databases, etc. Nowadays, the PRESS-GAMA database contains more than 14200 news items on natural hazards, climatic change or sustainable development, from which 12584 are from La Vanguardia.

On average for the period 1982-2007 the annual number of headlines related with topic 4 (mainly forest fires and droughts) was 122 (89 if they related only to Catalonia - r.C.) corresponding to 37 (23 r.C.) events. Topic 1 (mainly floods) achieves an average of 103 (58 r.C.) headlines per year, that correspond to 26 (11 r.C.) events. Topics 3 and 5 each represent each account for fewer than 65 headlines (50 r.C.) and 35 events ( 27 r.C.). Consequently, the number of headlines related with topic 4 is above that relating to topic 1, although floods and heavy rains are considered the main natural risk in Spain and also in Catalonia, due to their frequency and associated damages. Considering the high role of the press in building the social perception, these results indicate that floods are not perceived as being as frequent or dangerous as wildfires or droughts. Consequently, people can have a misguided notion of the danger associated with floods. Floodprone areas are more urbanized year by year, and false concepts of security (favored by some infrastructural measures of protection and by the idea that the Administration will take care of each person) drive people to imprudent behavior. For instance, people remain in their cars on flooded roads and water carries them away. In recent years such episodes have been at the root of more than $60 \%$ of the casualties by flood in Catalonia (Llasat et al., 2008).

Hazard, vulnerability, risk and press coverage have been analysed for two specific flood events in Catalonia in order to assess the press coverage of meteorological risks: the event between 9 and 12 April 2002, and the event between 8 and 10 October 2002. The former affected a region with low level of flood risk, in spite of its high frequency of heavy rainfalls; the latter affected one of the most flood-prone areas of Catalonia. In view of the climatology of the region, the hazard associated with the April flood event was greater that that associated with the October event, due to its higher frequency and rainfall intensity. However, the population density, the communication network, the presence of the airport and the urbanization of the floodplains, meant a greater vulnerability for the region affected by the October flood event and a greater impact, in spite of the lower precipitation and rainfall rate values. The media coverage of the two events was very different due to this different vulnerability. The results of the analysis reveal that the press focuses more on the vulnerability to risks (economic and social damage) and less on the actual danger (description and/or explanation of the meteorological phenomenon). It is also necessary to assess in each case all the situational factors involved in the publication of a news item, since the spatial and temporal location of the event need to be taken into account too (Llasat-Botija et al., 2007).

In the case of studies based on press data it becomes necessary to make use of meteorological databases too in order to get objective data of the different phenomena analyzed. The joint efforts of scientists and the media will be essential in constructing the social perception of risks and in making the information available to the most vulnerable population.

In addition, an analysis of evolution of the number of news items in the period of study shows a clearly rising trend. This may be due to various factors, such as a higher vulnerability and a lower tolerance threshold of the society with respect to risks. Finally, in a society as greatly influenced by the media as ours, and with new global meteorological risks such as climate change, scientists should work together with the media to make their research known to the general public, in particular as relates to the prevention of disasters caused by meteorological phenomena.

Acknowledgements. The present study was supported by the European Project FLASH FP6-2005-Global-4 (n. 036852). It was carried out within the framework of the WMO Project MEDEX and the HYMEX project. The authors wish to thank C. A. Doswell III for his comments on a first draft of this paper. Our thanks to $L a$ Vanguardia for access to its archive.

Edited by: F. Guzzetti

Reviewed by: M. Brilly and another anonymous referee

\section{References}

Allan, S., Adam, B., and Carter, C. (Eds.): Environmental Risks and the Media, London and New York: Routledge, xiv, 278 pp., 2000 .

Altava-Ortiz, V., Barrera, A., Llasat, M. C., Prat, M. A., GibergansBáguena, J., and Barnolas, M.: Application of the MM5 and the analogous method to heavy rainfall event, the case of 16-18 October 2003 in Catalonia (NE Spain), Adv. Geosci., 7, 313-319, 2006, http://www.adv-geosci.net/7/313/2006/. 
Barnolas, M. and Llasat, M. C.: A flood geodatabase and its climatological applications: the case of Catalonia for the last century, Nat. Hazards Earth Syst. Sci., 7, 271-281, 2007, http://www.nat-hazards-earth-syst-sci.net/7/271/2007/.

Beck, U.: Risk Society: Towards a New Modernity, Published in association with Theory, Culture \& Society, Sage Publications Ltd., 251 pp., 1992.

Blaikie, P., Cannon, T., Travis, I., and Wisner, B.: At Risk: Natural Hazards, People's vulnerability and Disasters, Routledge, New York, 1994.

Brilly, M. and Polic, M.: Public perception of flood risks, flood forecasting and mitigation, Nat. Hazards Earth Syst. Sci., 5, 345355,2005 , http://www.nat-hazards-earth-syst-sci.net/5/345/2005/.

Burton, I., Kates, R. W., and White, G. E.: The environment as hazard, Oxford University Press, 239 pp., 1978.

Cardona, O. D.: Natural disasters, global change and sustainable development: a strategy for reducing effects, in: III Meeting of the Scientific advisory Council for the International GeophereBiosphere Programme, Forum on Earth System Research, ICSU, Ensenada, Baja California, Mexico, 1993.

Cardona, O. D.: Manejo ambiental y prevención de desastres: dos temas asociados, Ciudades en Riesgo, in: Ciudades en Riesgo: Degradación Ambiental, riesgos urbanos y desastres, edited by: Fernández, M. A., La RED, USAID (reprinted as Cities at Risk, 1999), Lima, 1996.

Cardona, O. D.: The need for rethinking the concepts of vulnerability and risk from a holistic perspective: A necessary review and criticism for effective risk management, in: Mapping vulnerability: disasters, development and people, edited by: Bankoff, G., Frerks, G., and Hilhorst, D., Earthscan, London, 2004.

Cutter, S. L.: Living with risk. The geography of technological hazards, Arnold, London-New York, 214 pp., 1993.

DGPC - Directorate-General for Civil Protection: Special Emergency Flood Plan for Catalonia (INUNCAT), Government of Catalonia, 2006.

Delitala, A. M. S.: Perception of intense precipitation events by public opinion, Nat. Hazards Earth Syst. Sci., 5, 499-503, 2005, http://www.nat-hazards-earth-syst-sci.net/5/499/2005/.

Douglas, M. and Wildavsky, A.: Risk and Culture: An Essay on the Selection of Technological and Environmental Dangers, University of California Press, 215 pp., 1983.

Duce Díaz, E.: El medio natural como problema social: los aspectos hídricos en el diario La Vanguardia (1970-1990), in: El Agua y el Clima, Publicaciones de la Asociación Española de Climatología (AEC), Serie A, 3, 407-416, 2002.

Enander, A.: Risk perception in a wider context: how do the results from FLOWS fit with other studies on risk perception?, in: FLOWS Third International Conference, Conference report, 2005.

Fischer, H. W.: Response to disaster: Fact versus Fiction and its perpetuation: The sociology of disasters, New York, University Press of America, 1998.

García Codrón, J. C. and Silió Cervera, F.: Riesgos Naturales en los Andes: Cambio Ambiental, Percepción y Sostenibilidad, B. Asoc. Geogr. Esp., 30, 69-84, 2000.

Guzzetti, F., Stark, C. P., and Salvati, P.: Evaluation of flood and landslide risk to the population of Italy, Environ. Manage., 36(1), 15-36, 2005.
Hoffman, S. and Oliver-Smith, A. (Eds): Catastrophe and Culture. The Anthropology of Disater, The School of American Research Press, Santa Fe, New Mexico, 2002.

Kundzewicz, Z. W. and Mendel, L.: Flood risk and vulnerability in the changing world, in: International conference Towards natural flood reduction strategies, Warsaw, 2003.

Lacey, C. and Longman, D.: The Press as Public Educator: Cultures of Understanding, Cultures of Ignorance, University of Luton Press, Luton, 228 pp., 1997.

Lastoria, B., Simonetti, M. R., Casaioli, M., Mariani, S., and Monacelli, G.: Socio-economic impacts of major floods in Italy from 1951 to 2003, Adv. Geosci., 7, 223-229, 2006, http://www.adv-geosci.net/7/223/2006/.

Legrand, P., Brugnot, G., and Baumont, G.: Rétour d'experience des inondations de septembre de 2002 dans les départaments du Gard, de l'Hérault, du Vaucluse, des Bouches de Rhône, de l'Ardèche et de la Drôme. Contribution du Groupe d'Appui et d'expertisse scientifique, CD-ROM, 2003.

Llasat, M. C.: An objective classification of rainfall events on the basis of their convective features: application to rainfall intensity in the Northeast of Spain, Int. J. Climatol., 21, 1385-1400, 2001.

Llasat, M. C.: High magnitude storms and floods, in: The Physical Geography of the Mediterranean, edited by: Woodward, J. C., Oxford University Press, Oxford, 513-540, 2009

Llasat, M. C., Rigo, T., and Barriendos, M.: The "Montserrat-2000" flash-flood event: a comparison with the floods in the Northeastern Iberian Peninsula since the 14th century, Int. J. Climatol., 23, 453-469, 2003.

Llasat, M. C., Llasat-Botija, M., Barnolas, M., López, L., and Altava-Ortiz, V.: An analysis of the evolution of hydrometeorological extremes in newspapers: the case of Catalonia, 19822006, Nat. Hazards Earth Syst. Sci., 9, 1201-1212, 2009, http://www.nat-hazards-earth-syst-sci.net/9/1201/2009/.

Llasat-Botija, M., Llasat, M. C., and López, L.: Natural Hazards and the press in the western Mediterranean region, Adv. Geosci., 12, 81-85, 2007, http://www.adv-geosci.net/12/81/2007/.

Llasat, M. C. and Llasat-Botija, M.: Climate change and the perception of the risk of flooding in Catalonia, in: Public perception and policy of climate change in Catalonia, edited by: Tàbara, J. D., CADS, Barcelona, 55-69, 2008

Mariani, S., Casaioli, M., Accadia, C., Llasat, M. C., Pasi, F., Davolio, S., Elementi, M., Ficca, G., and Romero, R.: A limited area model intercomparison on the "Montserrat-2000" flashflood event using statistical and deterministic methods, Nat. Hazards Earth Syst. Sci., 5, 565-581, 2005, http://www.nat-hazards-earth-syst-sci.net/5/565/2005/.

Messner, F. and Meyer, V.: Flood damage, vulnerability and risk perception - Challenges for flood damage research, in: Flood Risk Management: Hazards, Vulnerability and Mitigation Measures, edited by: Schanze, J., Zeman, E., and Marsalek, J., Springer, 149-167, 2006

Milelli, M., Llasat, M. C., and Ducrocq, V.: The cases of June 2000, November 2002 and September 2002 as examples of Mediterranean floods, Nat. Hazards Earth Syst. Sci., 6, 271-284, 2006, http://www.nat-hazards-earth-syst-sci.net/6/271/2006/.

Nunes Correia, F., Fordham, M., Saraiva, M., and Bernardo, F.: Flood Hazard Assessment and Management: Interface with the Public, Water Resour. Manag., 12, 209-227, 1998. 
Platt, R. H.: Disaster and democracy: The politics of extreme natural events, Island Press, Washington, DC, 320 pp., 1999.

Plapp, T.: Perception and Evaluation of Natural Risks. Interim report on first results of a survey in six districts in Germany. Risk Research and Insurance Management, Working Paper No. 1, 11 pp., November 2001.

Serra, A., Tous, C., and Tàbara, J. D.: Climate change in the Catalan press, 1990-2006, in: Public perception and policy of climate change in Catalonia, edited by: Tàbara, J. D., CADS, Barcelona, 71-80, 2008.

Skiple Ibreek, A., Krasovkaia, I., Gottschalk, L., and Berg, H.: Perception and communication of flood risk - preliminary results from the FLOWS Project, in: International conference on innovation advances and implementation of flood forecasting technology, Norway, 2005.

Slovic, P.: Perception of risk: reflections on the psychometric paradigm, in: Social theories of risk, edited by: Krimsky, S. and Golding, D., New York, Praeger, 117-152, 1992.

Slovic, P.: Perception of risk, Science, 236, 280-285, 1997.
Slovic, P.: Perception of Risk, in: The perception of risk, edited by: Löfstedt, R. E., Earthscan, London, 220-315, 2000.

Slovic, P. and Weber, E. U.: Perception of Risk posed by extreme events, in: Risk Management strategies in an Uncertain World, Palisades, New York, 12-13 April 2002.

Tingsanchali, T. and Karim, M. F.: Flood hazard and risk analysis in the southwest region of Bangladesh, Hydrol. Process., 19, 20552069, 2005.

UNISDR: UNISDR Terminology on Disaster Risk Reduction, available at: http://www.unisdr.org/eng/terminology/ terminology-2009-eng.html, 2009.

Whyte, A. V. T.: From hazard perception to human ecology, in: Geography, resources, and environment, edited by: Kates, R. W. and Burton, I., University of Chicago Press, 2 pp., 1986.

Weber, E. U.: Decision and choice: Risk, empirical studies, in: International Encyclopedia of the Social and Behavioral Sciences, Oxford, UK, edited by: Smelser, N. J. and Baltes, P. B., Elsevier Science Limited, 11274-11276, 2001. 